\title{
Major Approaches on the Piezoelectric Device, Drills and Saws to Orthognathic Surgery: A Systematic Review
}

\author{
Diego César Marques,2,3, Vanessa Gabriela Gonzáles Pinto1,2, Rogério Luiz de Araújo Vian²,4, \\ Regis Manzini'2, Leandro Aparecido Irrazabal5, Priscilla Janaína de Lima Borelli Bovo², \\ Idiberto José Zotarelli Filho1,2*, Elias Naim Kassis ${ }^{1,2}$ \\ ${ }^{1}$ University Center North Paulista (Unorp), São José do Rio Preto (SP), Brazil \\ ${ }^{2}$ Post Graduate and Continuing Education (Unipos), São José do Rio Preto (SP), Brazil \\ ${ }^{3}$ Cristo Redentor Hospital, Iporá, Goáis, Brazil \\ ${ }^{4}$ Santa Casa de Misericórdia Hospital, Serviço de Cirurgia e Traumatologia Bucomaxilofacial, Ribeirão Preto (SP), Brazil \\ ${ }^{5}$ Universida de Federal do Pampa (Unipampa), Campus Uruguaiana (RS), Brazil \\ Email: *scientificresearch@unipos.com.br
}

How to cite this paper: Marques, D.C., Pinto, V.G.G., de Araújo Vian, R.L., Manzini, R., Irrazabal, L.A., de Lima Borelli Bovo, P.J., Filho, I.J.Z. and Kassis, E.N. (2019) Major Approaches on the Piezoelectric Device, Drills and Saws to Orthognathic Surgery: A Systematic Review. Health, 11, 783-791.

https://doi.org/10.4236/health.2019.116063

Received: April 16, 2019

Accepted: June 17, 2019

Published: June 20, 2019

Copyright $\odot 2019$ by author(s) and Scientific Research Publishing Inc. This work is licensed under the Creative Commons Attribution International License (CC BY 4.0).

http://creativecommons.org/licenses/by/4.0/

\section{c) (i) Open Access}

\begin{abstract}
Introduction: The incidence of lesions of sensory and motor nerves associated with oral and maxillofacial surgery is often underestimated, representing around $32.0 \%$ of all lesions, and orthognathic surgery contributes $12.3 \%$ to these lesions. Thus, the use of piezosurgery (PiZCi) has been indicated in several procedures within oral and maxillofacial surgery due to a number of advantages over conventional drill and saw techniques. Objective: to analyze the main literature on the use of the piezoelectric device in relation to the use of drills and to orthognathic surgery in dentistry. Methods: A total of 41 articles were found involving Orthognathic Surgery, Piezoelectric Device, Drills Device, Saws Device, and Efficiency. Initially, it was held the exclusion existing title and duplications following the interest described this work. After this process, the summaries were evaluated, and a new exclusion was held. 29 articles were included and discussed in this study. Initially, the keywords were determined by searching the DeCS tool (Descriptors in Health Sciences, BIREME base) and later verified and validated by MeSh system (Medical Subject Headings, the US National Library of Medicine). Results and conclusion: It was concluded that the piezoelectric device has excelled with an effective surgical technique, being able to be indicated in the most diverse areas of the oral surgery, providing accurate, clean and minimally traumatic osteotomies for the soft tissues, intraoperative bleeding, when compared to conventional surgery using drills and/or saws.
\end{abstract}




\section{Keywords}

Orthognathic Surgery, Piezoelectric Device, Drills Device, Saws Device, Efficiency

\section{Introduction}

The incidence of lesions of sensory and motor nerves associated with oral and maxillofacial surgery is often underestimated, accounting for about $32.0 \%$ of all lesions [1] [2]. Nerve changes in the region of innervation of the inferior alveolar, lingual and facial nerves cause significant disorders for patients with varying degrees of dysfunction and aesthetic impairment, and orthognathic surgery contributes $12.3 \%$ to these lesions [2].

In this scenario, orthognathic surgery is a successful alternative in the correction of severe dentofacial deformities, providing alterations in the region of the oropharynx [3]. The main advantages of this procedure are to establish a harmonious facial aesthetic, an optimal functional occlusion and the improvement of airway conditions, which are the most important goals of orthodontic-surgical treatment [3] [4]. However, sensorial deficiencies including paresthesia, hypoesthesia and dysesthesia due to inferior alveolar nerve injury are still frequently reported due to the use of saws and drills during osteotomy, as well as indirect damage during the movement of the bone segments and the formation of hematoma or near edema of the mandibular canal after surgery, besides the type of fixation used to stabilize the osteotomized segments [4].

In this way, the piezoelectric technique (PiZ) with ultrasonic vibrations is also used in hard tissues and is standing out as an efficient alternative with minimal damage [2] [3] [4]. Thus, the use of piezo-surgery (PiZCi) has been indicated in several procedures within oral and maxillofacial surgery due to a series of advantages proposed by the manufacturers [4].

The use of PiZCi has been associated with a characteristic called "selective cutting", in which the ultrasonic vibration of the tips would act specifically on mineralized tissues through the cavitation effect, performing precise cuts of bone, providing a better visualization of the operative field, with absence of soft tissue injuries (dura mater, mucous membranes and nervous tissue), as well as a reduction of transoperative bleeding, with lower vibration, thus reducing the patient's stress in procedures under local anesthesia when compared to the instruments conventional [5].

Therefore, the present study analyzed the main literary findings on the use of the piezoelectric device in relation to the use of drills and to orthognathic surgery in dentistry.

\section{Methods}

\subsection{Eligibility and Study Design}

A total of 41 articles were found involving Orthognathic Surgery, Piezoelectric 
Device, Drills Device, Saws Device, and Efficiency. Initially, it was held the exclusion existing title and duplications following the interest described this work. After this process, the summaries were evaluated, and a new exclusion was held. 29 articles were included and discussed in this study.

Experimental and clinical studies were included (case reports, retrospective, prospective, randomized trials and systematic review and meta-analysis) with qualitative and/or quantitative analysis. Initially, the keywords were determined by searching the DeCS tool (Descriptors in Health Sciences, BIREME base) and later verified and validated by MeSh system (Medical Subject Headings, the US National Library of Medicine) in order to achieve consistent search, following the rules of systematic review-PRISMA (Transparent reporting of systematic reviews and meta-analyses http://www.prisma-statement.org/).

\section{Flow Chart}

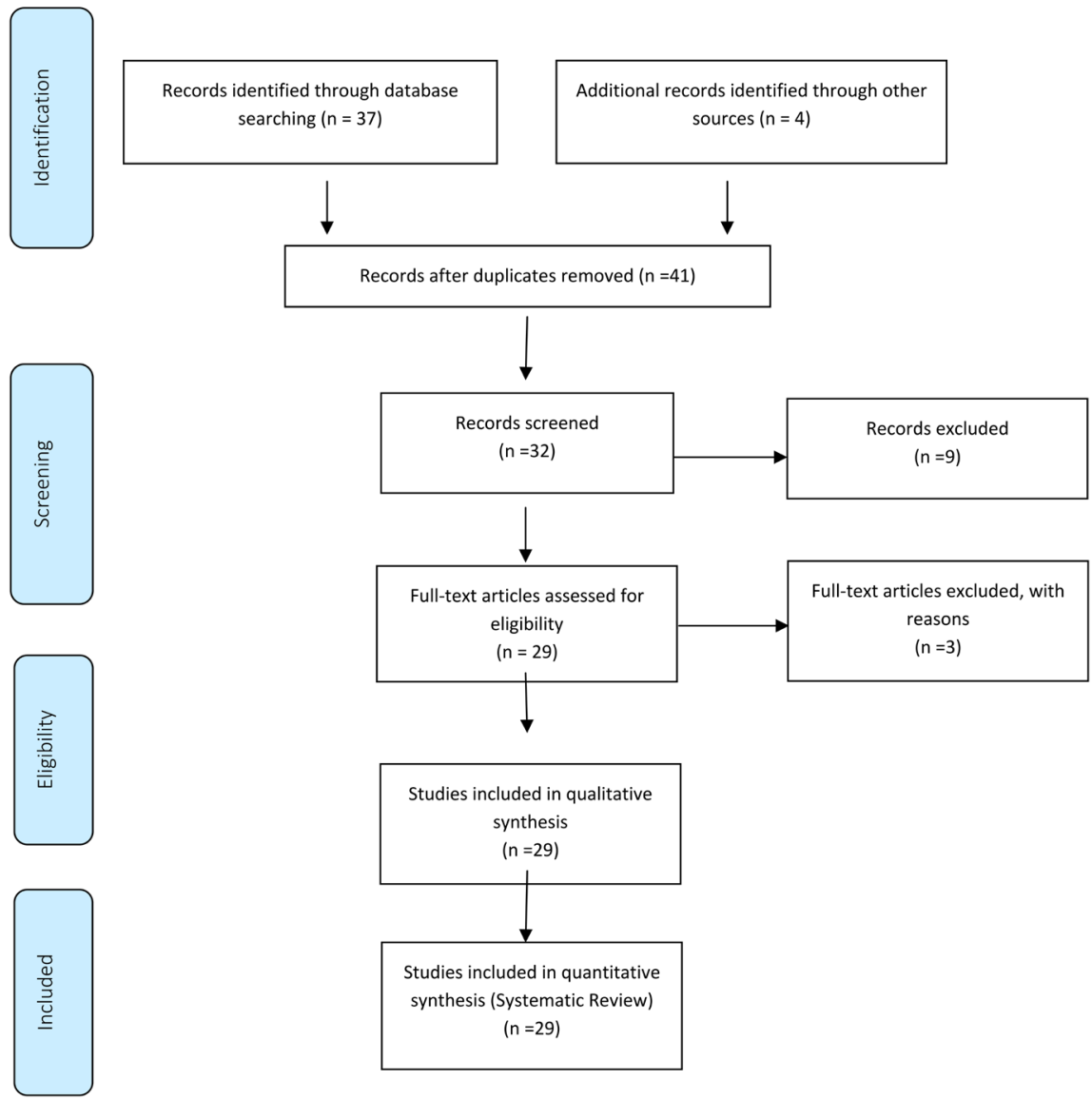

\subsection{Literature Review and Discussion}

Based on the proposal of the present paper through, through the major literary findings on the advantages and disadvantages of orthognathic surgical techniques for osteotomies, surgical techniques for osteotomies, several studies have presented satisfactory results in favor of PiZ [1].

In this regard, a systematic review study was conducted to investigate the 
available evidence on maxillary complications related to piezoelectric and conventional surgery [1]. A total of 996 maxillary osteotomies were analyzed, 864 performed with conventional tools and 132 with PiZ. One hundred and fifty-six complication events were reported. Complications, in descending order of general prevalence, were: Sensorineural disturbance (64.7\%), hemorrhage (8.3\%), oroantral communication (7.7\%), soft tissue injury (7.7\%), infection (3.2\%), osteonecrosis $(1.9 \%)$ and permanent nerve damage (1.3\%). Among the complications, the results showed the highest prevalence of the sensorineural disorder, with hemorrhage being the most frequently reported complication and the second most prevalent complication [1].

In relation to oral surgeries, the advantages apply to the protection of noble structures, such as the inferior alveolar nerve, and reducing postoperative edema due to less surgical trauma [2] [3]. In large surgeries, PiZ has shown good results in simplifying the surgical technique, reducing the incidence of transoperative complications [4] [5].

In implantology, it is often necessary to perform procedures to restore bone volume sufficient for implant installation [4]. Several techniques of bone grafting with the use of autogenous block or particulate bone for the reconstruction of these defects can be performed with the use of PiZ [5].

Thus, it is noted that the use of PiZ is in the performance of procedures close to noble structures, such as vessels and nerves, demonstrating excellent results, minimizing and, in some cases, avoiding injuries, even when direct contact of the device with these structures occurs [5]. Also, when used in maxillary sinus elevation procedures, where the preservation of the Schneider's membrane is necessary, better results have been observed, mainly due to the reduction of the risk of perforation of the sinus, besides providing a reduction of the postoperative edema by the minor surgical trauma [5].

Another previous study compared the drill and piezoelectric (PiZ) techniques, being groups A (drill) and B (piezoelectric), it was observed shortly after the osteotomy, in both groups, edges of the wound and blood clot. On the third day, the presence of bone spicules was observed in group A (drill) differently from group B, and both groups showed the onset of bone neoformation. On the day after the osteotomy in both groups, the presence of pre-osteoblasts was observed. On the seventh-day bone formation may already be observed in both groups [6].

Furthermore, in relation to the lifting sinus technique, it is important to keep Schneider's membrane intact to become the receptor site for the bone graft, stabilizing the graft material during the repair period. The main complication in the use of this technique is the possibility of accidental perforation of the membrane. The drilling rate reported in the literature ranges from $12.0 \%$ to $58.0 \%$ with the use of saw and drill instruments [7] [8].

Leclercq et al. [9] studied some clinical applications of PiZCi in relation to the use of saws, drills, and chisels, such as atraumatic removal of osseointegrated implants, removal of grafts in retromolar and mentonian regions, and lateraliza- 
tion of inferior alveolar nerve. It showed greater safety for the surgeon, offering greater comfort to the patient, reducing the trauma caused by drills, saws, and chisels. The procedure facilitated actions near the inferior alveolar nerve. However, the device presented deficiencies in relation to the fragility of the tips and the longer operative time spent.

Thus, several papers have presented these advantages of the use of PiZ in the maxillary sinus survey. Vercellotti et al. [10] presented a success rate of $95 \%$. The study proved that this technique simplifies maxillary sinus surgery and reduces the possibility of postoperative complications.

In this sense, the application of PiZ in dentistry has been used routinely, mainly in implant surgeries. Thus, Heiland et al. [11] described advantages in relation to shear accuracy, the absence of trauma in adjacent tissues and clean field for visualization. It demonstrated the treatment in patients with periodontal surgeries and the possibility of using PiZ in the oral cavity. The operative time reported as a disadvantage of the method [11].

Furthermore, Heiland et al. [11] treated patients with periodontal surgeries, sinus membrane elevations, dental extractions, root recessions and splitting of the bone crest. The work showed the possibility of using piezoelectric surgery (PiZCi) in the oral cavity, presenting advantages in relation to cutting precision, the absence of trauma in adjacent tissues and clean field for visualization. The disadvantage of the method was due to the operative time.

In this context, according to the work of Ueki et al. of comparison between PiZ and drills, the bone instrumentation performed with PiZ offers three main advantages compared to conventional drills, such as precise cutting, the safety of work and less damage to the tissue [12]. By means of the photomicrographs of the osteotomies performed, it was observed that in the group which the drill was used as an instrument, all the preparations presented bone spikes differently from the PiZ group that presented the best result. Thus, the use of the drill bit as a working tool requires more biological work [12].

In this scenario, the use of PiZ for maxillary sinus elevation has been highlighted, due to the selective cut for hard tissues, preserving the soft tissues of possible lesions caused by rotating instruments [13] [14]. Also, it reduces the risk of perforation of the membrane during the procedures and increases the trans-operative visibility due to the better control in the bleeding, besides providing greater operative comfort [14].

Another study by Chiriac et al. [14] investigated the influence of intraoral PiZ osteotomy in relation to bone morphology, cell viability, and differentiation. Samples of cortical bone slices were collected by PiZ and conventional drills. The study concluded that PiZautogenous bone slices contained vital cells that differed in osteoblasts compared to conventional osteotomies.

The main oral applications of PiZCi have been demonstrated in the non-traumatic removal of osseointegrated implants, removal of bone graft in the retromolar and symphysis regions, and in the lateralization of the inferior alveolar nerve [15] [16]. In addition, Berengo et al. [17] made a qualitative and quan- 
titative evaluation of autogenous bone harvested by different methods. The tissue was analyzed by microphotography and histomorphometric analysis, measuring the area of the fragments, the percentage of vital and necrotic bone and the number of osteocytes with evident nucleus per unit area. Chisels, high and low-speed drills, and PiZ were used. The best results were achieved with PiZ.

Also, other authors have described the use of PiZCi with less soft tissue tear, easy control during osteotomy and reduction of trauma in the patient caused by the inconvenience of conventional rotary cutters and disks [18] [19].

Barone et al. [20] performed a comparative study between conventional milling cutters and the PiZ in osteotomy and sinus membrane elevation, aiming at the implant installation. All of the maxillary sinuses were grafted using particulate bone. On one side were used conventional diamond cutters and the other PiZ ultrasound tips. The time required for osteotomy of the window with the device was greater. Perforations in the sinus membrane were in smaller percentage with the use of ultrasound (23\% vs 30\%) [21].

In addition, Kotrikowa et al. [22] described applications of PiZCi in relation to intraoral areas that can be used in implantology, dental extractions, removal of bone grafts, sinus lift bone window preparation and inferior alveolar nerve lateralization. The results showed that it is possible to treat bone tissue without injuring soft tissue.

Eggers et al. [23] stated that PiZCi offers three advantages compared to conventional milling cutters, precise cutting, job safety, and reduced tissue damage. The main clinical applications of the device are: in sinus lift surgeries, autogenous bone collector, implant surgeries and maxillofacial surgeries.

Another study compared in vitro $\mathrm{PiZ}$ and conventional drills on lateralization or transposition of the inferior alveolar nerve, evaluating the effects on soft and hard tissues [24]. On one side the nerve was discovered with conventional drills and another with the piezoelectric device [25]. The rotary drill produced a smooth cut at the end of the bone. PiZ produced an uneven surface. Irrigation fluid removed the bone particles during preparation and exposure of the alveolar nerve in both techniques. Initial healing of the wound was faster and, consequently, less chance of infection [26] [27].

In this sense, the author Vercellotti et al. [28] reviewed the principles of piezoelectricity and its clinical applications in oral surgeries, such as atraumatic extractions, clinical crown increase, periapical cyst debridement, sinus lift, fracture implant removal, bone removal from the retromolar and symphysis regions, and bone crest. He pointed out the advantages of this tool in relation to normal cutters, such as a clean and precise osteotomy, with little risk of traumatizing soft tissues and good access in difficult regions. However, although not invasive, the technique, because it is new, requires training for its effective use [29].

\subsection{Future Perspectives}

The prospects of using the piezoelectric device are intended to revolutionize the 
area of dental surgery, but the skill and training for its use by the professional should be taken into account since the device demands a longer surgical time compared to conventional drills and saws.

\section{Conclusion}

It was concluded that the piezoelectric device has excelled with an effective surgical technique, being able to be indicated in the most diverse areas of the oral surgery, providing accurate, clean and minimally traumatic osteotomies for the soft tissues, as well as reducing intraoperative bleeding when compared to conventional surgery using drills and/or saws.

\section{Acknowledgements}

We appreciate greatly the UNIPOS graduate for support and also UNORP of Sao Jose do Rio Preto/SP for the support.

\section{Conflicts of Interest}

The authors declare no conflicts of interest regarding the publication of this paper.

\section{References}

[1] Thereza-Bussolaro, C., Galván, J., Pachêco-Pereira, C. and Flores-Mir, C. (2019) Maxillary Osteotomy Complications in Piezoelectric Surgery Compared to Conventional Surgical Techniques: A Systematic Review. International Journal of Oral and Maxillofacial Surgery. https://doi.org/10.1016/j.ijom.2019.01.001

[2] Rossi, D., Romano, M., Karanxha, L., Baserga, C., Russillo, A., Taschieri, S., Del Fabbro, M., Giannì, A.B. and Baj, A. (2018) Bimaxillary Orthognathic Surgery with a Conventional Saw Compared with the Piezoelectric Technique: A Longitudinal Clinical Study. British Journal of Oral and Maxillofacial Surgery, 56, 698-704. https://doi.org/10.1016/j.bjoms.2018.07.011

[3] Raffaini, M., Perello, R., Conti, M., Hernandèz-Alfaro, F. and Agostini, T. (2018) A New Hybrid Technique for Performing a Safer Bilateral Sagittal Split Osteotomy: Combining Reciprocating Saw and Piezoelectric Devices. Facial Plastic Surgery, 34, 419-422. https://doi.org/10.1055/s-0038-1666788

[4] Bertossi, D., Nocini, R., Luciano, U., Galzignato, P.F., Ricciardi, G., Lucchese, A., Tacchino, U., Donadello, D., Lanaro, L., Gualdi, A., De Santis, D., Giampaoli, G. and Nocini, P.F. (2018) Piezoelectric Surgery Inserts vs Conventional Burst: A Clinical Investigation. Journal of Biological Regulators and Homeostatic Agents, 32, 15-19.

[5] Al Asseri, N. and Swennen, G. (2018) Minimally Invasive Orthognathic Surgery: A Systematic Review. International Journal of Oral and Maxillofacial Surgery, 47, 1299-1310. https://doi.org/10.1016/j.ijom.2018.04.017

[6] Gleizal, A., Bera, J.C., Lavandier, B. and Beziat, J.L. (2007) Piezoelectric Osteotomy: A New Technique for Bone Surgery-Advantages in Craniofacial Surgery. Childs Nervous System, 23, 509-513. https://doi.org/10.1007/s00381-006-0250-0

[7] Robiony, M., Polini, F., Costa, F., Vercellotti, T. and Politi, M. (2004) Piezoelectric Bone Cutting in Multipiece Maxillary Osteotomies. Journal of Oral and Maxillofa- 
cial Surgery, 62, 759-761. https://doi.org/10.1016/j.joms.2004.01.010

[8] Hoigne, D.J., Stubinger, S., Kaenel, O.V., Shamdasani, S. and Hasenboehler, P. (2006) Piezoelectric Osteotomy in Hand Surgery: First Experiences with a New Technique. BMC Musculoskeletal Disorders, 7, 36. https://doi.org/10.1186/1471-2474-7-36

[9] Leclercq, P., Zenati, C. and Dohan, D.M. (2008) Ultrasonic Bone Cut Part 2: State-of-the-Art Specific Clinical Applications. Journal of Oral and Maxillofacial Surgery, 66, 183-188. https://doi.org/10.1016/j.joms.2005.12.050

[10] Vercellotti, T. (2004) Technological Characteristics and Clinical Indications of Piezoelectric Bone Surgery. Minerva Stomatologica, 53, 207-214.

[11] Pohlenz, P., Blessmann, M., Blake, F., Li, L., Schmelzle, R. and Heiland, M. (2006) Outcome and Complications of 540 Microvascular Free Flaps: The Hamburg Experience. Clinical Oral Investigations, 11, 89-92.

[12] Ueki, K., Nakagawa, K., Marukawa, K., Shimada, M. and Yamamoto, E. (2007) Use of the Sonopet Ultrasonic Curettage Device in Intraoral Vertical Ramus Osteotomy. International Journal of Oral and Maxillofacial Surgery, 36, 745-747. https://doi.org/10.1016/j.ijom.2007.01.022

[13] Choung, P.H. (2007) Orthognathic Surgery. Journal of Oral and Maxillofacial Surgery, 1018, 1023-1036. https://doi.org/10.1016/j.ijom.2007.08.186

[14] Chiriac, G., Herten, M., Schwarz, F., Rothamel, D. and Becker, J. (2005) Autogenous Bone Chips: Influence of a New Piezoelectric Device (Piezosurgery) on Chip Morphology, Cell Viability and Differentiation. Journal of Clinical Periodontology, 32, 994-999. https://doi.org/10.1111/j.1600-051X.2005.00809.x

[15] Gruber, R.M., Kramer, F.J., Merten, H.A. and Schliephake, H. (2005) Ultrasonic Surgery: An Alternative Way in Orthognathic Surgery of the Mandible. A Pilot Study. International Journal of Oral and Maxillofacial Surgery, 34, 590-593. https://doi.org/10.1016/j.ijom.2005.06.006

[16] Stubinger, S., Kuttenberger, J., Filippi, A., Sader, R. and Zeilbofer, H.F. (2005) Intraoral Intraoral Piezosurgery: Preliminary Results of a New Technique. Journal of Oral and Maxillofacial Surgery, 63, 1283-1287. https://doi.org/10.1016/j.joms.2005.05.304

[17] Berengo, M., Bacci, C., Sartori, M., Perini, A., Barbera, M.D. and Valente, M. (2006) Histomorphometric Evaluation of Bone Grafts Harvested by Different Methods. Minerva Stomatologica, 55, 189-198.

[18] Kramer, F.J., Ludwig, H.C., Materna, T., Gruber, R., Merten, H.A. and Schliephake, H. (2006) Piezoelectric Osteotomies in Craniofacial Procedures: A Series of $15 \mathrm{Pe}-$ diatric Patients. Journal of Neurosurgery, 104, 68-71. https://doi.org/10.3171/ped.2006.104.1.68

[19] Robiony, M., Polini, F., Costa, F., Zerman, N. and Politi, M. (2007) Ultrasonic Bone Cutting for Surgically Assisted Rapid Maxillary Expansion (SARME) under Local Anaesthesia. International Journal of Oral and Maxillofacial Surgery, 36, 267-269. https://doi.org/10.1016/j.ijom.2006.08.013

[20] Barone, A., Santini, S., Marconcini, S. and Giacomelle, L. (2008) Osteotomy and Membrane Elevation during the Maxillary Sinus Augmentation Procedure. A Comparative Study: Piezoelectric Device vs. Conventional Rotative Instruments. Clinical Oral Implants Research, 19, 511-515. https://doi.org/10.1111/j.1600-0501.2007.01498.x

[21] Heiland, M., Blessmann, M., Pohlenz, P., Li, L., Schmelzle, R. and Blake, F. (2007) Intraoral Osteotomies Using Piezo Surgery for Distraction in an Infant with 
Pierre-Robin Sequence. Clinical Oral Investigations, 11, 303-306. https://doi.org/10.1007/s00784-006-0091-y

[22] Kotrikowa, B., Wirtz, R., Krempien, R., Blank, J. and Eggers, G. (2006) Piezosurgery: A New Safe Technique in Cranial Osteoplasty? International Journal of Oral and Maxillofacial Surgery, 35, 461-465. https://doi.org/10.1016/j.ijom.2005.12.006

[23] Eggers, G., Klein, J., Blank, J. and Hassfeld, S. (2004) Piezosurgery: An Ultrasound Device for Cutting Bone and Its Use and Limitations in Maxillofacial Surgery. British Journal of Oral and Maxillofacial Surgery, 42, 451-453. https://doi.org/10.1016/j.bjoms.2004.04.006

[24] Schaller, B.J., Gruber, R., Merten, H.A., Kruschat, T., Schliephake, H., Buchfelder, M., et al. (2005) Piezoelectric Bone Surgery: A Revolutionary Technique for Minimally Invasive Surgery in Cranial Base and Spinal Surgery? Technical Note. Neurosurgery, 57, E410. https://doi.org/10.1227/01.NEU.0000176700.77461.C9

[25] Ueki, K., Nakagawa, K., Maruakawa, K., Yamamoto, E. and Le Fort, I. (2004) Osteotomy Using an Ultrasonic Bone Curette to Fracture the Pterygoid Plates. Journal of Cranio-Maxillofacial Surgery, 32, 381-386. https://doi.org/10.1016/j.jcms.2004.06.005

[26] Metzger, M.C., Bormann, K.H., Schoen, R. and Gellrich, N.C. (2006) Inferior Alveolar Nerve Transposition-An in Vitro Comparison between Piezosurgery and Conventional Bur Use. Journal of Oral Implantology, 32, 19-25. https://doi.org/10.1563/1548-1336(2006)32[19:IANTIV]2.0.CO;2

[27] Covani, U. and Barone, A. (2007) Piezosurgical Treatment of Unicystic Ameloblastoma. Journal of Periodontology, 78, 1342-1347. https://doi.org/10.1902/jop.2007.060417

[28] Vercellotti, T. (2000) Piezoelectric Surgery in Implantology: A Case Report-A New Piezoelectric Ridge Expansion Technique. International Journal of Periodontics \& Restorative Dentistry, 20, 358-365.

[29] Labanca, M., Azzola, F., Vinci, R. and Rodella, L.F. (2008) Piezoelectric Surgery: Twenty Years of Use. British Journal of Oral and Maxillofacial Surgery, 46, 265-269. https://doi.org/10.1016/j.bjoms.2007.12.007 